\title{
Particle Velocity and Deposition Efficiency in the Cold Spray Process
}

\author{
D. L. Gilmore, R. C. Dykhuizen, R. A. Neiser, T. J. Roemer*, and M. F. Smith
}

Sandia National Laboratories, Albuquerque, NM 87185-1130

PECEIVED

*Ktech Corporation, Albuquerque, NM 87106-4265

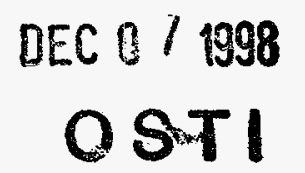

Copper powder was sprayed by the cold-gas dynamic method. In-flight particle velocities were measured with a laser-two-focus system as a function of process parameters such as gas temperature, gas pressure, and powder feed rate. Particle velocities were uniform in a relatively large volume within the plume and agreed with theoretical predictions. The presence of the substrate was found to have no significant effect on particle velocities. Cold-spray deposition efficiencies were measured on aluminum substrates as a function of particle velocity and incident angle of the plume. Deposition efficiencies of up to $95 \%$ were achieved. The critical velocity for deposition was determined to be about 640 meters per second.

\section{Introduction}

The cold-gas dynamic spray method (CGSM), hereafter referred to simply as cold spray, is a relatively new process by which coatings of ductile materials, or composite materials with significant ductile phase content, may be produced without significant heating of the sprayed powder. There is no evidence to date for melting during the deposition process, but the kinetic energy of the particles is sufficient to produce large deformations and high interfacial pressures and temperatures, which appear to produce a solid-state bond. 


\section{DISCLAIMER}

This report was prepared as an account of work sponsored by an agency of the United States Government. Neither the United States Government nor any agency thereof, nor any of their employees, make any warranty, express or implied, or assumes any legal liability or responsibility for the accuracy, completeness, or usefulness of any information, apparatus, product, or process disclosed, or represents that its use would not infringe privately owned rights. Reference herein to any specific commercial product, process, or service by trade name, trademark, manufacturer, or otherwise does not necessarily constitute or imply its endorsement, recommendation, or favoring by the United States Government or any agency thereof. The views and opinions of authors expressed herein do not necessarily state or reflect those of the United States Government or any agency thereof. 


\section{DISCLAIMER}

Portions of this document may be illegible in electronic image products. Images are produced from the best available original document. 
Cold-spray processing was developed in the former Soviet Union more than a decade ago as an offshoot of supersonic wind tunnel testing (Ref 1-3). Research in the U. S. has been conducted so far through a consortium of companies organized by the National Center for Manufacturing Sciences (Ref 4-6). The current investigation is a follow up to recent efforts to model the aerodynamics of the supersonic flow of the particles in the converging-diverging spray nozzle (Ref 7). In-flight particle velocities were measured at various positions in the spray plume for a range of gun inlet pressures and temperatures. Deposition efficiencies were also measured as functions of particle velocity and gun-substrate angle.

\section{Experimental Procedures}

Figure I shows a schematic of the experimental set-up used in this work (Ref 4). The converging-diverging gun nozzle was manufactured out of tool steel and contains a $2 \mathrm{~mm}$ diameter circular throat. The exit aperture is rectangular, $2 \mathrm{~mm}$ wide by $10 \mathrm{~mm}$ long. The distance between the throat and exit aperture is $80 \mathrm{~mm}$, and the nozzle expands linearly in one dimension. A Praxair Thermal Spray Products (Appleton, WI) Model 1270 HP computerized high-pressure powder hopper, using standard high pressure gas fittings and equipped with an ultra-fine powder wheel, was used to feed the powder. The powder was fed axially into the gun nozzle $25 \mathrm{~mm}$ upstream of the throat. The feed tube had an inside diameter of $2.2 \mathrm{~mm}$. The hopper was elevated above the gun, with a wheel rotational speed of $1.0 \mathrm{rpm}$ unless otherwise noted. The powder carrier gas pressure was held $69 \mathrm{kPa}(10 \mathrm{psi})$ above the main gas pressure in order to improve the feed of the fine powders used. All pressures in this paper are reported relative to the local atmospheric pressure, approximately $83 \mathrm{kPa}$ (12 psi). The temperature of the main gas flow prior to entering the gun was measured with a type $\mathrm{K}$ flow-through thermocouple and was varied between 25 and $500{ }^{\circ} \mathrm{C}$ with a simple resistance heater. The powder carrier gas was not heated. Although it is possible to use a powder gas that is different from the main driver gas, in this work the gases were of the same type for a given run, with dry air used in some experiments and helium used in others. 
The velocity of a powder particle in a gas flow should vary inversely with the square root of the particle diameter $(\operatorname{Ref} 7)$, and thus finer powders should have higher impact velocities for a given set of spray parameters. However in practice, difficulty in feeding very fine powders usually limits the minimum size that is feasible to spray. All results in this paper are for a spherical, gasatomized copper powder (ACuPowder 500A). Two lots were used, one with a mean diameter of $19 \mu \mathrm{m}$ and the other a mean of $22 \mu \mathrm{m}$. The size distributions, as measured by a Coulter LS-100 laser diffraction system, are summarized in Table 1, and the powder morphology can be seen in Figures $2 \mathrm{a}$ and $2 \mathrm{~b}$. The oxygen content of the powder was $0.336 \pm 0.008$ weight percent. Velocity data were acquired with a laser-two-focus (L2F) velocimeter (Ref 8 ). The photomultiplier gains were kept constant, and the difference between channel count rates was kept to a minimum by adjusting the attenuation coefficients prior to each run. The depth of focus for the L2F is approximately the same as the width of the spray plume upon exiting the gun nozzle $(2 \mathrm{~mm})$, so some variance from theoretical calculations of center line behavior may be expected.

Deposition efficiencies were measured on $51 \mathrm{~mm} \times 51 \mathrm{~mm} \times 3 \mathrm{~mm}$ thick grit-blasted aluminum substrates $(6061 \mathrm{~T} 6)$. The substrates were cleaned with an acetone bath followed by a methanol bath, air dried, and then weighed on a digital electronic balance. The substrates were weighed again after spraying in order to calculate the weight gain. Deposition efficiency was calculated as the weight gain divided by the product of the calibrated mass feed rate and the spray time on the substrate. No allowance was made for the weight of substrate material which may have been removed during spraying, as this was generally far less than the weight of the deposited coating. Deposition efficiencies were measured as functions of substrate impact angle and particle velocity. The standoff distances used for the formation of deposits were between 10 and $25 \mathrm{~mm}$. Compared with most thermal spray systems, in-flight particle characteristics for the cold-spray process change very little with varying standoff distance, as will be described in the next section. 


\section{Results and Discussion}

\subsection{In-flight Particle Velocities}

Figure 3a displays the variation of mean particle velocity and count rate with $y$-axis distance from the center line of the gun (see Figure 1 for orientation). At a z-axis (stand-off) distance of 25 $\mathrm{mm}$ from the gun exit, the velocities drop off only $5 \%$ over a region that corresponds to roughly two-thirds of the nozzle exit length. Similar velocity distributions were observed at $10 \mathrm{~mm}$ from the gun exit. The corresponding particle frequency counts drop off more quickly along the $y$-axis, with the region of maximum particle flow remaining close to the central gun axis (z) as might be expected with axial powder injection. Thus the vast majority of the particles reside in the constant velocity region. Figure $3 \mathrm{~b}$ shows the variation in mean particle velocity and count rate along the $\mathrm{x}$ axis. Although the velocity drop-off is somewhat steeper than that observed along the $y$-axis, mean particle velocities at the edge of the plume are still greater than $85 \%$ of those in the center.

The variation of mean particle velocities with $z$-axis (standoff) distance is shown in Figure 4.

With air as the driving gas and inlet conditions of $2.1 \mathrm{MPa}(300 \mathrm{psi})$ and $200^{\circ} \mathrm{C}$, the particles have been accelerated to their peak velocity, just under $400 \mathrm{~m} / \mathrm{s}$, by the time they exit the nozzle. They maintain this velocity almost constant out to a distance of $50 \mathrm{~mm}$ from the exit plane of the nozzle, past which point the velocity decreases roughly linearly, diminishing by about $3 \%$ over the next 50 $\mathrm{mm}$. When helium is used as the driving gas, the particles are still accelerating out to a distance of about $30 \mathrm{~mm}$. Due to the lower density of helium, the drag force on the particles is lower than for air at a given gas velocity relative to the particles. Therefore the distance required for the particles to reach a given fraction of the velocity of the driving gas (which is the limiting velocity) will be: greater for helium than for air (Ref 7). Theoretical calculations for the conditions shown in Figure 4 indicate that at the gun exit, the particles will have reached $42 \%$ of the gas velocity when helium is used, and $62 \%$ of the gas velocity when air is used. However, since the helium velocity is 2.5 times that of air, higher particle velocities are still observed with helium as the driving gas. 
The flow of a high velocity gas jet normal to a solid barrier will create a high pressure region close to the surface. This high pressure region might be thought to affect the velocity of the inflight particles. In order to determine if this is the case, $\mathrm{L} 2 \mathrm{~F}$ velocity measurements were taken at a $\mathrm{z}$-axis distance of $8 \mathrm{~mm}$ from the gun exit, $2 \mathrm{~mm}$ above a substrate, using room temperature air as the driving gas. These measurements were then repeated without the presence of the substrate. Measurements could not be reliably obtained closer to the substrate due to the rapid build-up of the coating and scattering of the laser beam. It can be seen in Figure 5a that the presence of the substrate has no effect on the velocity distribution curves. This result agrees with theoretical modeling which predicts that for a $10 \mathrm{~mm}$ standoff distance the gas jet does not begin to slow significantly until approximately $1 \mathrm{~mm}$ above the substrate. For a particle moving at $400 \mathrm{~m} / \mathrm{s}$, this leaves less than $3 \mu$ s before particle impact, too short a time for the region of stagnant gas to significantly decelerate the powder. Figure $5 \mathrm{~b}$ shows theoretical calculations for fully-dense copper particles in a flow of air with gun inlet conditions of $2.1 \mathrm{MPa}(300 \mathrm{psi})$ and $27^{\circ} \mathrm{C}$. The gas velocity at the gun exit is $600 \mathrm{~m} / \mathrm{s}$. This figure shows that the particles would need to be smaller than $5 \mu \mathrm{m}$ in diameter to be slowed by more than $10 \%$ before impact (Ref 9$)$.

The effect of mass loading on particle velocity was investigated. Figure 6 shows that, above about 0.5 grams per second, the mean particle velocity decreases linearly with the mass feed rate, which is directly proportional to the powder hopper wheel rotational speed. The decrease in velocity may be attributed to the increased mass that the gas flow must accelerate. However, powder feed rates of above 1.5 grams per second might still be used, as the velocity decrease is only about $5 \%$.

Supersonic fluid flow theory predicts that the particle velocities should vary as the log of the gas stagnation pressure (Ref 7$)$. Figure 7 indicates that the experimental data for inlet gas temperatures of 25 and $300^{\circ} \mathrm{C}$ are fit well by a logarithmic curve, although the measured values fall slightly below those predicted by the one-dimensional flow theory. This shortfall may be 
explained in part by the fact that the theoretical values are calculated assuming an isentropic (adiabatic and frictionless) gas expansion in the gun after the throat. Under real world experimental conditions, obvious energy exchange between the gas and the nozzle walls is observed: for example, when running without pre-heating the main gas, water vapor condenses on the gun; and when running with a main gas inlet temperature of $300^{\circ} \mathrm{C}$, the outside of the gun becomes too hot to touch with the bare hand.

Figure 8 indicates the variation in particle velocity which is obtained with changes in gas temperature and gas type. Switching from air to helium for the driving gas results in a large increase in mean particle velocity. This is due to the increase in gas velocity obtained with the lower molecular weight gas. Increasing the temperature of the main gas flow also allows higher gas velocities to be achieved for a given pressure (Ref 7,10$)$. This increase in gas velocity outweighs the corresponding decrease in gas density, so the drag on the particles increases. There is fairly good agreement observed between the experimental velocity measurements and the predicted values, especially for the air data. However, the leveling off of the measured particle velocities at higher gas temperatures is not well understood. This effect may be attributed to nonisentropic expansion as noted above, or to the fact that the unheated powder gas may not be mixing well with the surrounding main gas flow after injection into the gun. That is, the gas conditions in the gun may be significantly different from the well-mixed state assumed for modeling. This effect should be more pronounced at higher temperatures because the main gas flow decreases with temperature for a given pressure, while the powder gas flow remains roughly constant.

\subsection{Coating Deposition}

The cold-spray process has been shown to be capable of rapidly applying coatings over large areas (Ref 1,2). High deposition efficiencies have been reported for some material-substrate combinations, such as copper onto copper (Ref 1). In the current work, coating thicknesses of 4-5 $\mathrm{mm}$ were found to be easily achievable. No attempt was made to determine if there is an upper limit 
on coating thickness. The footprint of the spray plume on the substrate at a standoff distance of 25 $\mathrm{mm}$ was approximately $12 \mathrm{~mm}$ by $3 \mathrm{~mm}$. The $12 \mathrm{~mm}$ width of the coating was consistent with the divergence angle of the nozzle. This observation was supported by L2F observations of in-flight particle trajectories. The oxygen content of the coatings was $0.28 \pm 0.005$ weight percent, somewhat less than that of the starting powder $(0.336 \pm 0.008$ weight percent). The cause of this decrease is not known. It may be due to preferential deposition of low-oxide-content particles at the expense of high-oxide-content particles.

Figure 9a shows the effect of mean particle velocity on the deposition efficiency of copper on an aluminum substrate oriented normal to the gun axis. Since the effective substrate material changes from aluminum to copper as the coating is deposited, it might be expected that there would be a dependence of the deposition efficiency on coating thickness. However, this was not observed. Data for the deposition of copper on copper and aluminum on copper are also given for comparison $(\operatorname{Ref} 1,4)$. The data presented in this paper are similar to the earlier data for coppercopper deposition up to approximately $50 \%$ deposition efficiency, but show considerably higher efficiencies at particle velocities of $700 \mathrm{~m} / \mathrm{s}$. Not enough details are available on the experimental set-up or alloy compositions used in the previous work to be able to speculate as to the possible causes for this difference.

It should be noted that mean particle velocities may not be the best way to determine the critical velocity necessary for deposition. Figure $9 \mathrm{~b}$ displays the measured velocity distribution curves for deposition efficiencies of $0 \%$ (just beginning to deposit), $53 \%$, and $95 \%$. It can be seen that, although the mean particle velocity for incipient deposition is roughly $500 \mathrm{~m} / \mathrm{s}$, a critical velocity of about $640 \mathrm{~m} / \mathrm{s}$ fits the observed data quite well - the $0 \%$ curve is almost entirely below this value, the $53 \%$ curve is split, and the $95 \%$ curve is almost entirely above this value.

The data show that deposition efficiency is a sensitive function of particle impact velocity and particle-substrate composition. Figure $9 \mathrm{c}$ indicates that the gun-substrate angle (which should be very close to the incident angle of particle impact for thin coatings) also strongly influences the 
build-up of the cold-spray coating. This effect seems to be primarily linked to the decrease in the component of particle velocity normal to the substrate, as seen in Figure $9 \mathrm{~d}$. An impact angle of $60^{\circ}$, corresponding to a normal velocity component of 324 meters per second for a $22 \mu \mathrm{m}$ copper powder sprayed with $200^{\circ} \mathrm{C}, 2.1 \mathrm{MPa}$ (300 psi) helium, resulted in slight erosion of the aluminum substrate. The divergence of the curves in Figure $9 \mathrm{~d}$ may indicate that other factors besides the normal component of velocity have a significant effect at low deposition efficiencies.

\section{Conclusions}

This work investigates both the in-flight characteristics of copper particles in a supersonic cold-spray plume and the build-up of the subsequent coating on aluminum substrates. Velocities were found to be relatively constant within a large volume of the plume. Particle counts dropped off sharply away from the central axis. The presence of a substrate was found to have no effect on the velocity of the particles. A substantial mass-loading effect on the particle velocity was observed; particle velocities begin to drop as the mass ratio of powder to gas flow rates exceeds $3 \%$. The measured variation of velocity with gas pressure and pre-heat temperature was in fairly good agreement with theoretical predictions. Helium may be used as the driving gas instead of air in order to achieve higher particle velocities for a given temperature and pressure. Coating deposition efficiencies were found to increase with particle velocity and decrease with gunsubstrate angle. There did not appear to be any dependence of the deposition efficiency on coating thickness. A critical velocity for deposition of about $640 \mathrm{~m} / \mathrm{s}$ appears to fit the data well.

The cold-spray technique shows promise as a method for the deposition of materials which are thermally sensitive or may experience rapid oxidation under typical thermal spray conditions. High deposition efficiencies are achievable for certain coating-substrate conditions. Work remains to determine the material and microstructural properties which govern the coating process. 


\section{Acknowledgments}

The authors would like to acknowledge the work of Amalia Lopez in running the computer simulations of particle drag used to create Figure 5b. Ken Eckelmeyer provided the metallography of the copper powder shown in Figure 2, and Jeffery Reich performed the oxygen analyses of the powder and coatings.

Sandia is a multiprogram laboratory operated by Sandia Corporation, a Lockheed Martin Company, for the United States Department of Energy under Contract DE-AC04-94AL85000. 


\section{References}

1. A. P. Alkhimov, V. F. Kosarev, and A. N. Papyrin, A Method of Cold Gas-Dynamic Deposition, Dokl. Akad. Nauk. SSSR, Vol. 315 (No. 5), 1990, pp. 1062-1065.

2. A. P. Alkhimov, A. N. Papyrin, V. F. Kosarev, N. I. Nesterovich, and M. M. Shuspanov, Gas Dynamic Spraying Method for Applying a Coating, U. S. patent 5,302,414, April 12, 1994.

3. A. O. Tokarev, Structure of Aluminum Powder Coatings Prepared by Cold Gas-Dynamic Spraying, Met. Sci. Heat Treat., Vol. 38 (No. 3-4), 1996, pp. 136-139.

4. R. C. McCune, A. N. Papyrin, J. N. Hall, W. L. Riggs, and P. H. Zajchowski, An Exploration of the Cold Gas-Dynamic Spray Method for Several Materials Systems, Advances in Thermal Spray Science and Technology, C. C. Berndt and S. Sampath, Eds., ASM International, 1995, pp. 1-5.

5. R. C. McCune, W. T. Donoon, E. L. Cartwright, A. N. Papyrin, E. F. Rybicki, and J. R. Shadley, Characterization of Copper and Steel Coatings Made by the Cold Gas-Dynamic Spray Method, Thermal Spray: Practical Solutions for Engineering Problems, C. C. Berndt, Ed., ASM International, 1996, pp. 397-403.

6. T. H. VanSteenkiste et al., Kinetic Spray Coatings, Surf. Coat. Technol., 1998, in press.

7. R. C. Dykhuizen and M. F. Smith, Gas Dynamic Principles of Cold Spray, J. Therm. Spray Technol., Vol. 7 (No. 2), 1998, pp. 205-212.

8. M. F. Smith, T. J. O'Hern, J. E. Brockmann, R. A. Neiser, and T. J. Roemer, A Comparison of Two Laser-Based Diagnostics for Analysis of Particles in Thermal Spray Streams, Advances in Thermal Spray Science and Technology, C. C. Berndt and S. Sampath, Eds., ASM International, 1995, pp. 105-110.

9. A. R. Lopez, private communication, Sandia National Laboratories, Albuquerque, NM, 1998.

10. R. H. Sabersky, A. J. Acosta, and E. G. Hauptmann, Fluid Flow: A First Course in Fluid Mechanics, 3rd ed., Macmillan, 1989. 


\section{Figures}

1. Schematic of experimental set-up, indicating reference axes. Not to scale.

2. (a) SEM image of gas-atomized copper powder used in experiments.

(b) SEM image of powder cross-section, indicating near full density.

3. (a) Mean particle velocity and counts versus $y$-axis position $(x=0, z=25 \mathrm{~mm}) .19 \mu \mathrm{m}$ copper powder; $25^{\circ} \mathrm{C}, 2.1 \mathrm{MPa}$ ( $300 \mathrm{psi}$ ) helium driving gas.

(b) Mean particle velocity and counts versus $x$-axis position ( $y=0, z=25 \mathrm{~mm}) .19 \mu \mathrm{m}$ copper powder; $25^{\circ} \mathrm{C}, 2.1 \mathrm{MPa}(300 \mathrm{psi})$ helium driving gas.

4. Mean particle velocity versus $z$-axis position $(x=0, y=0) .22 \mu \mathrm{m}$ copper powder; $200^{\circ} \mathrm{C}$, $2.1 \mathrm{MPa}(300 \mathrm{psi})$ helium driving gas.

5. (a) Particle velocity distributions, with and without substrate. Measurements at $z=8 \mathrm{~mm}$ (2 $\mathrm{mm}$ above substrate, when present). $22 \mu \mathrm{m}$ copper powder; $25^{\circ} \mathrm{C}, 2.1 \mathrm{MPa}$ (300 psi) air driving gas.

(b) Theoretical calculations of particle deceleration near substrate. Fully dense copper powder; $27^{\circ} \mathrm{C}, 2.1 \mathrm{MPa}$ (300 psi) air driving gas; $10 \mathrm{~mm}$ gun standoff.

6. Mean particle velocity versus mass loading ( $\mathrm{z}=10 \mathrm{~mm}$ ). $22 \mu \mathrm{m}$ copper powder; $25^{\circ} \mathrm{C}, 2.1$ $\mathrm{MPa}(300 \mathrm{psi})$ air driving gas; 805 SLPM total gas flow.

7. Mean particle velocity versus gas pressure $(z=10 \mathrm{~mm}) .22 \mu \mathrm{m}$ copper powder; $25^{\circ} \mathrm{C}$ and $300^{\circ} \mathrm{C}$ air driving gas.

8. Mean particle velocity versus gas type and temperature $(z=10 \mathrm{~mm}) .22 \mu \mathrm{m}$ copper powder; $2.1 \mathrm{MPa}(300 \mathrm{psi})$ air and helium driving gases.

9. (a) Deposition Efficiency vs. Mean Particle Velocity

(b) Particle Velocity Distributions

(c) DE vs. Impact angle; Helium, $300 \mathrm{psig}, 200^{\circ} \mathrm{C}$; $\mathrm{X}$ standoff $=25 \mathrm{~mm} ; 22 \mu \mathrm{m}$ Copper

(d) DE vs. normal velocity 
Table 1. Powder size distributions (micrometers)

\begin{tabular}{|c|c|c|c|c|c|}
\hline Powder & $10 \%>$ & $25 \%>$ & $50 \%>$ & $75 \%>$ & $90 \%>$ \\
\hline 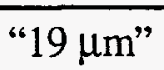 & 25.9 & 22.7 & 18.7 & 14.5 & 10.9 \\
\hline " $22 \mu \mathrm{m}$ " & 28.5 & 25.6 & 22.2 & 18.2 & 14.4 \\
\hline
\end{tabular}


Figure 1 (Ref 4)

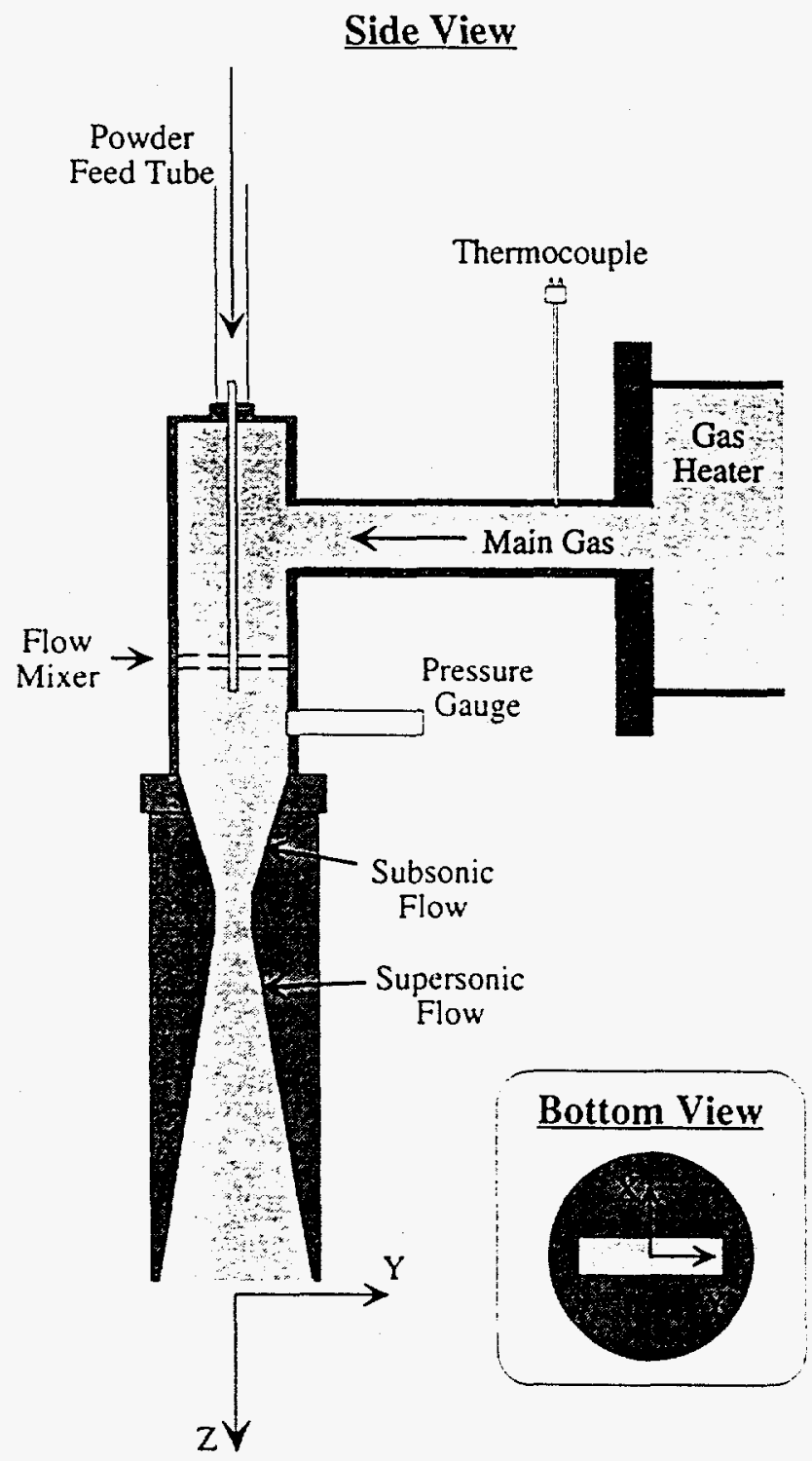


Figure 2a

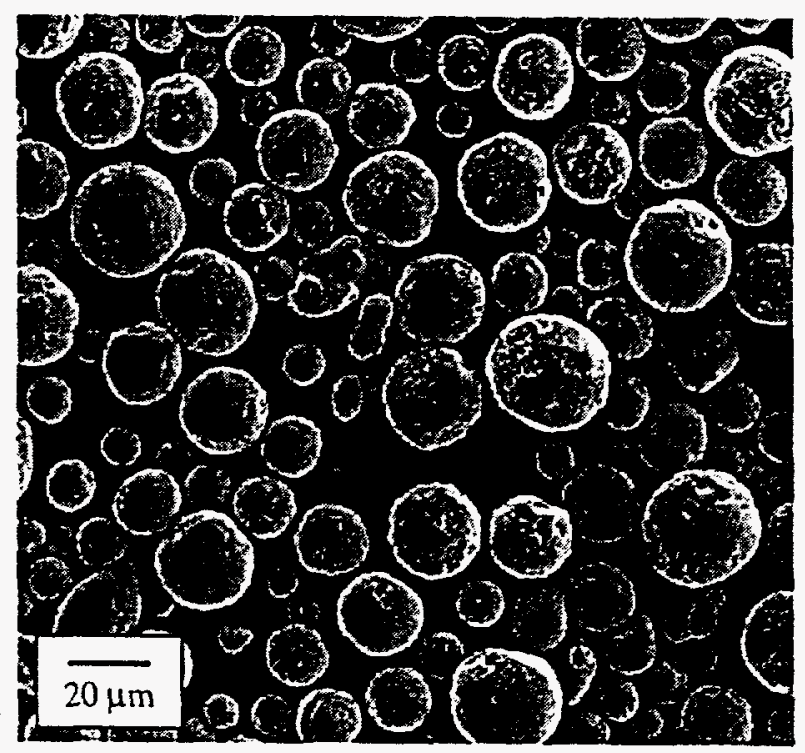


Figure 2b

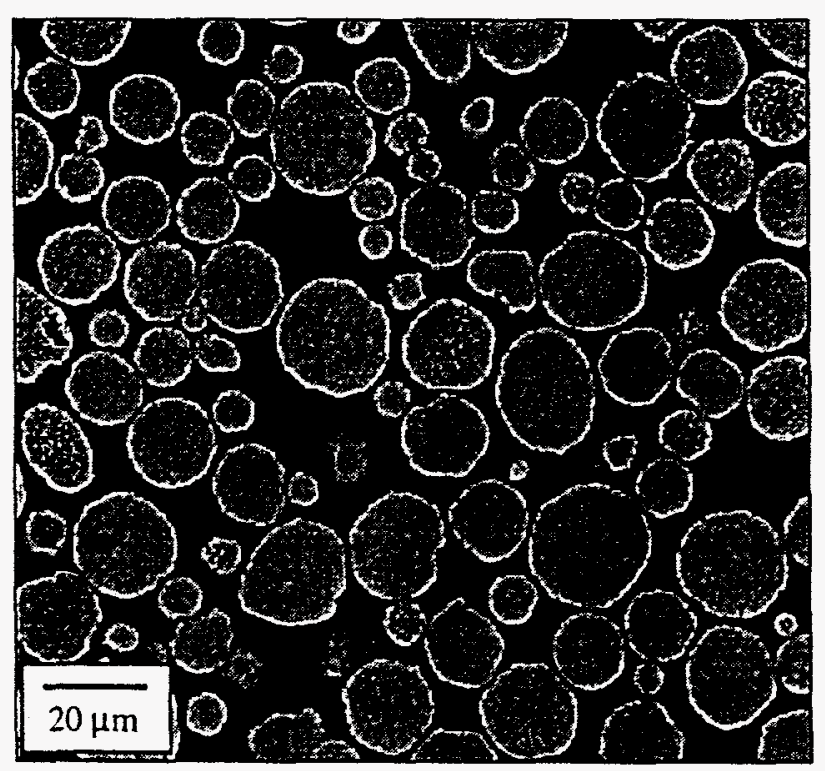


Figure $3 a$

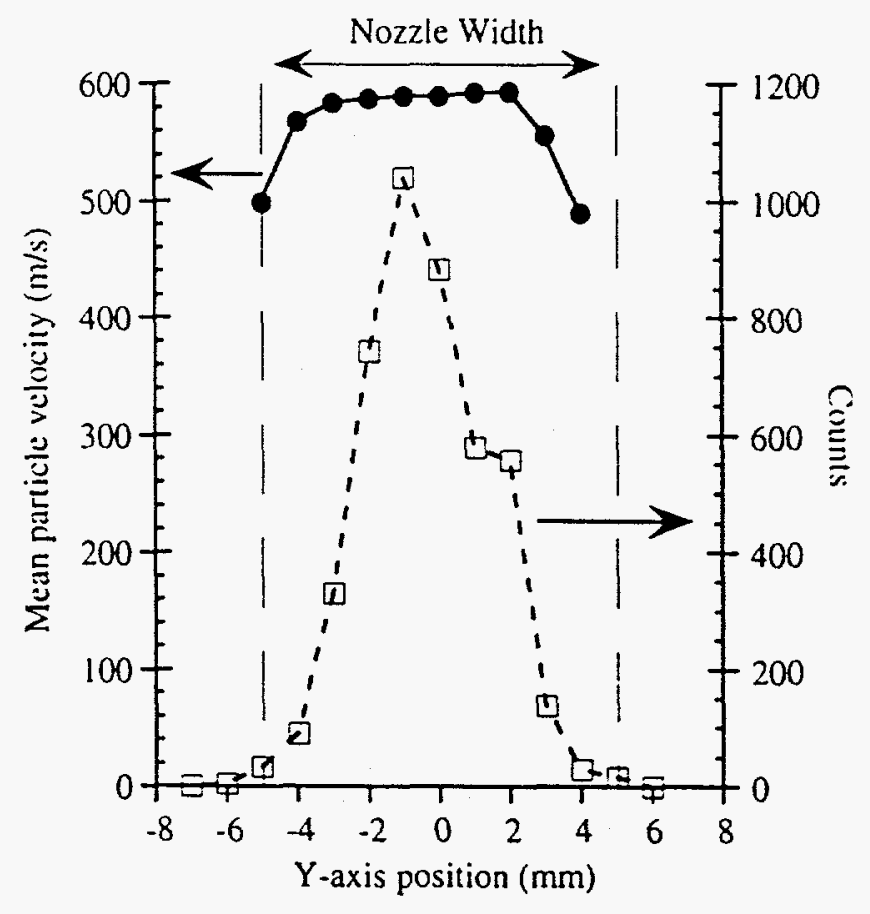


Figure $3 b$

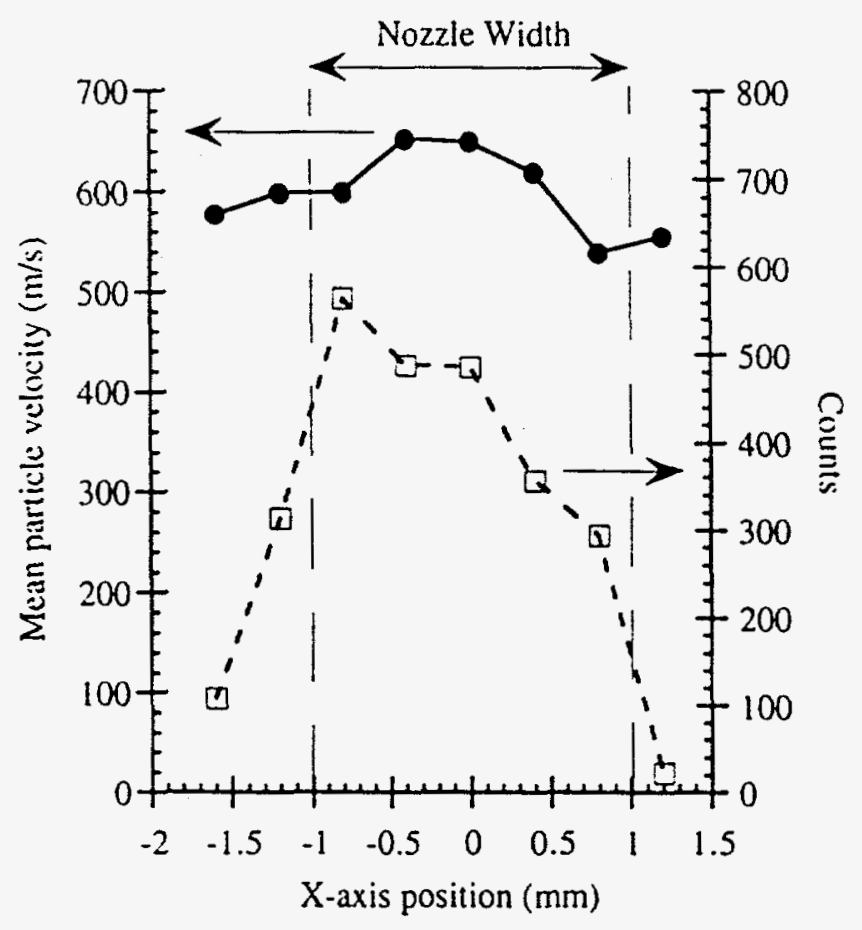


Figure 4

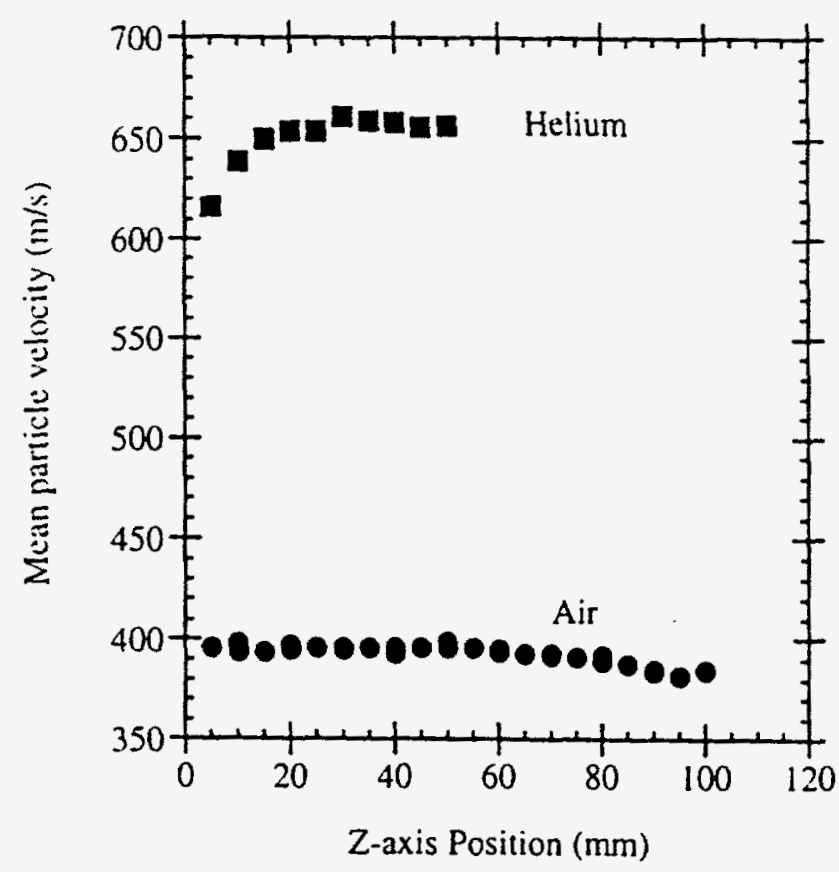


Figure 5a

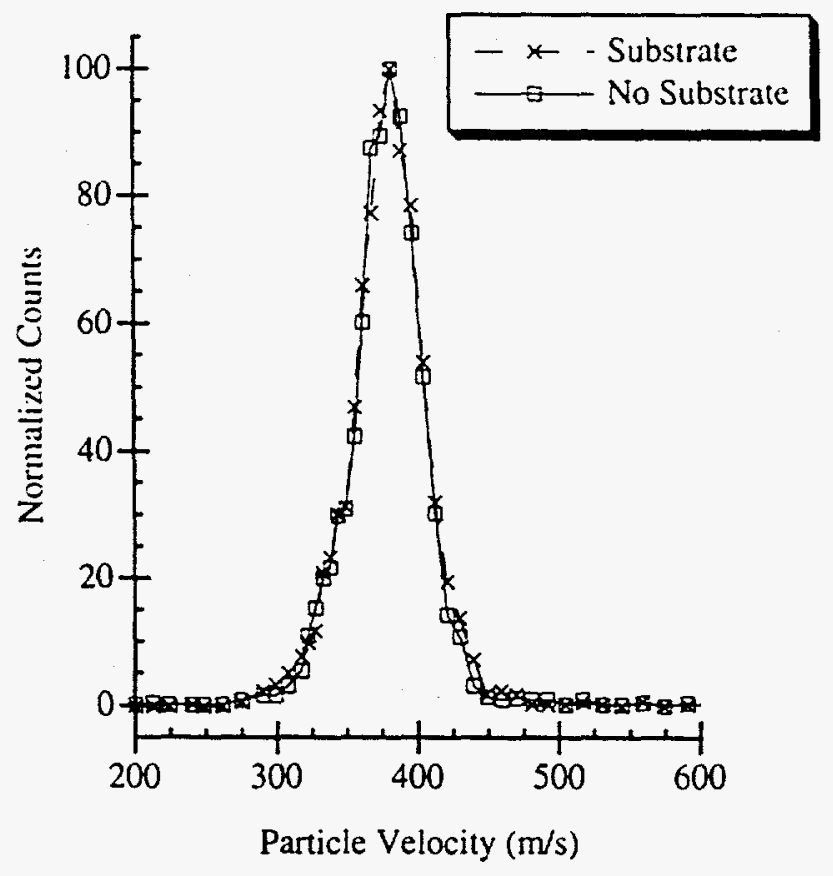




\section{Figure 5b}

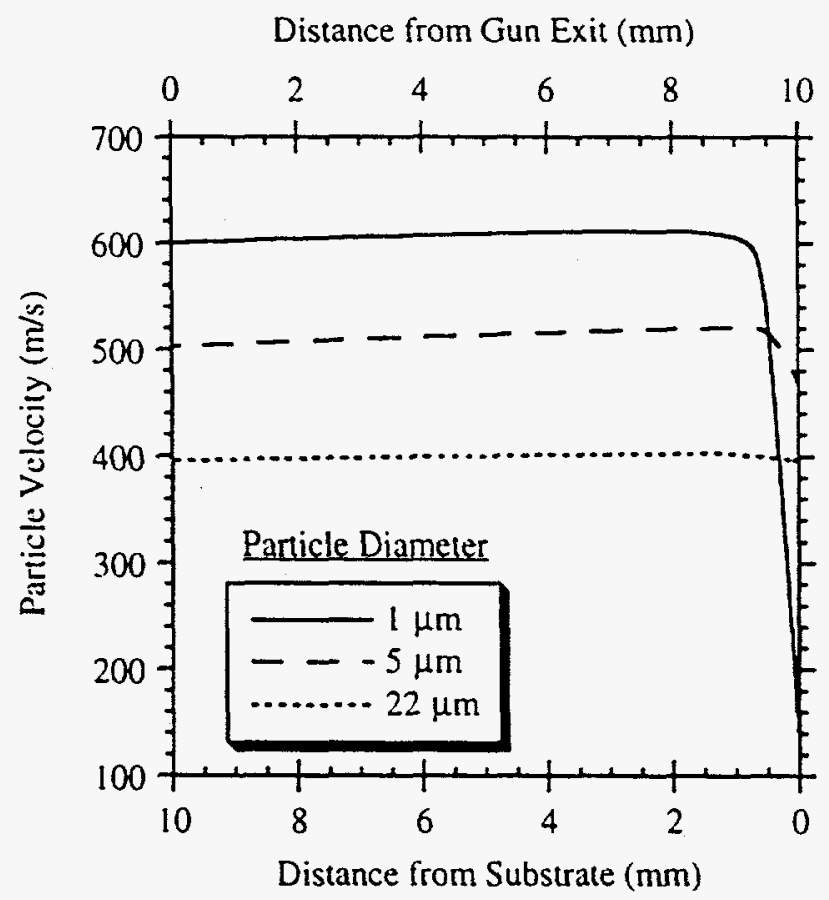




\section{Figure 6}

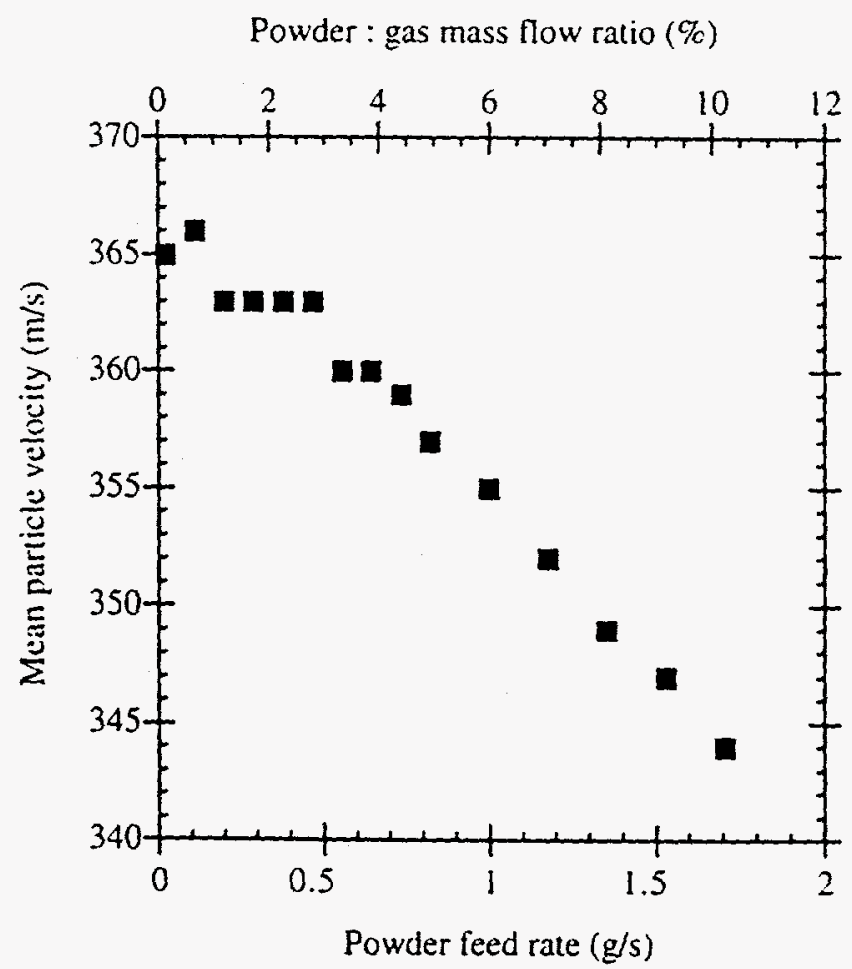




\section{Figure 7}

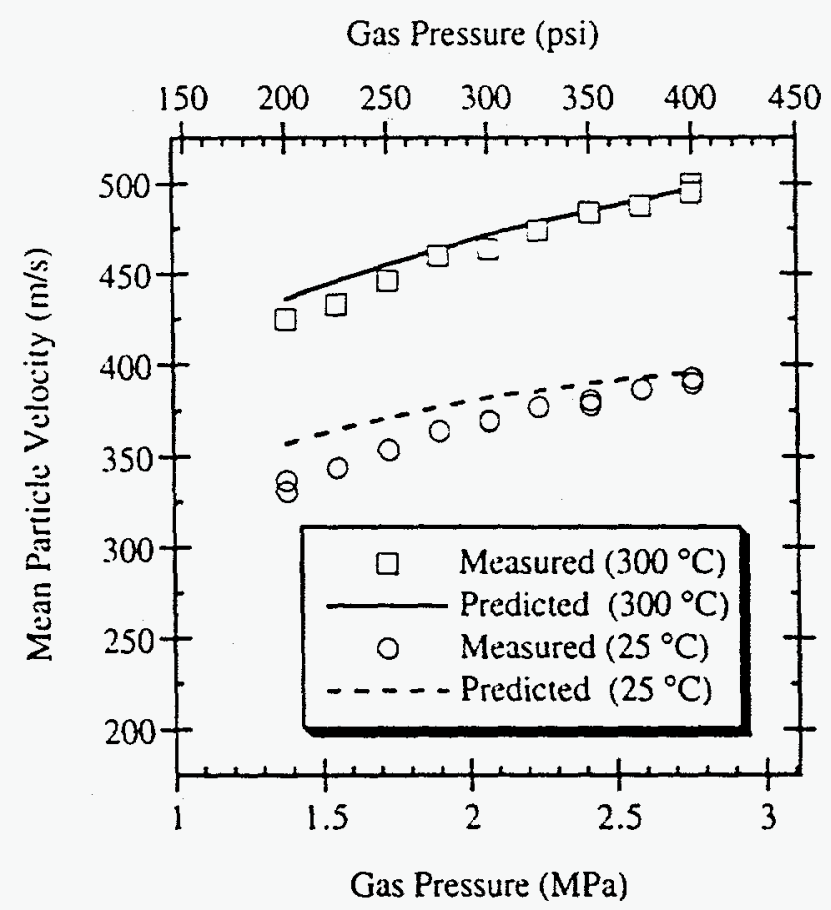




\section{Figure 8}

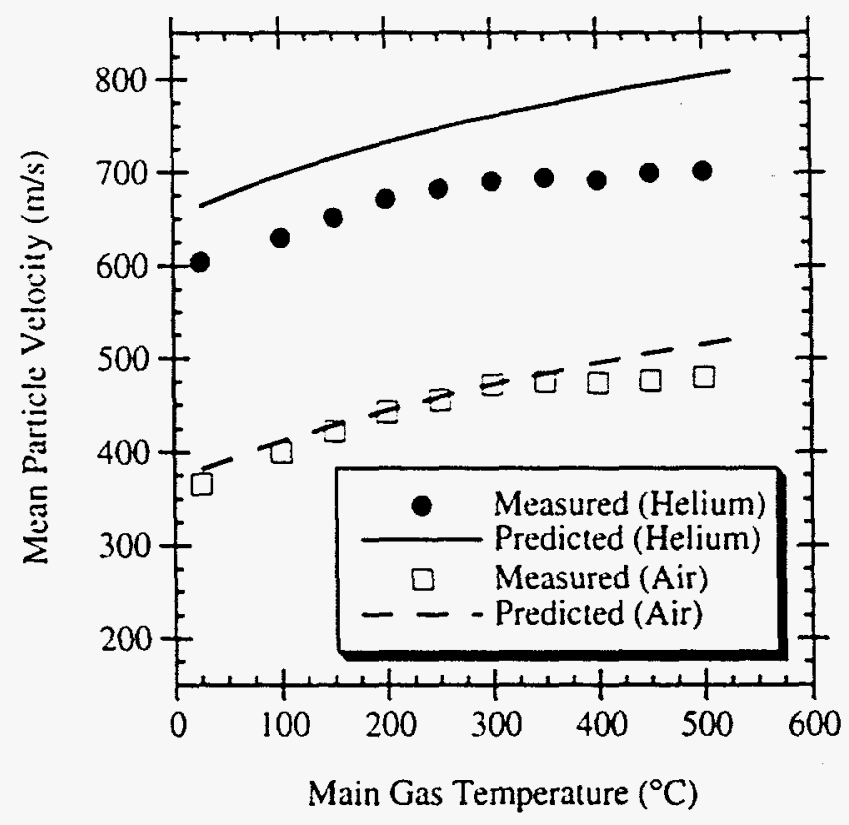


Figure $9 a$

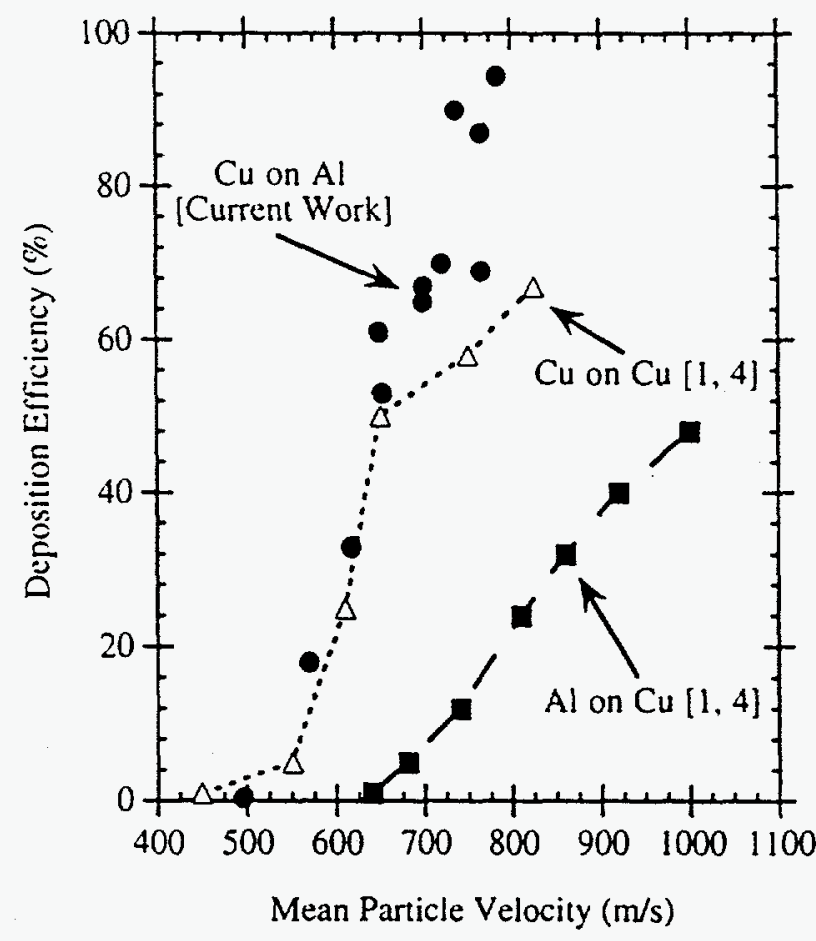


Figure 9b

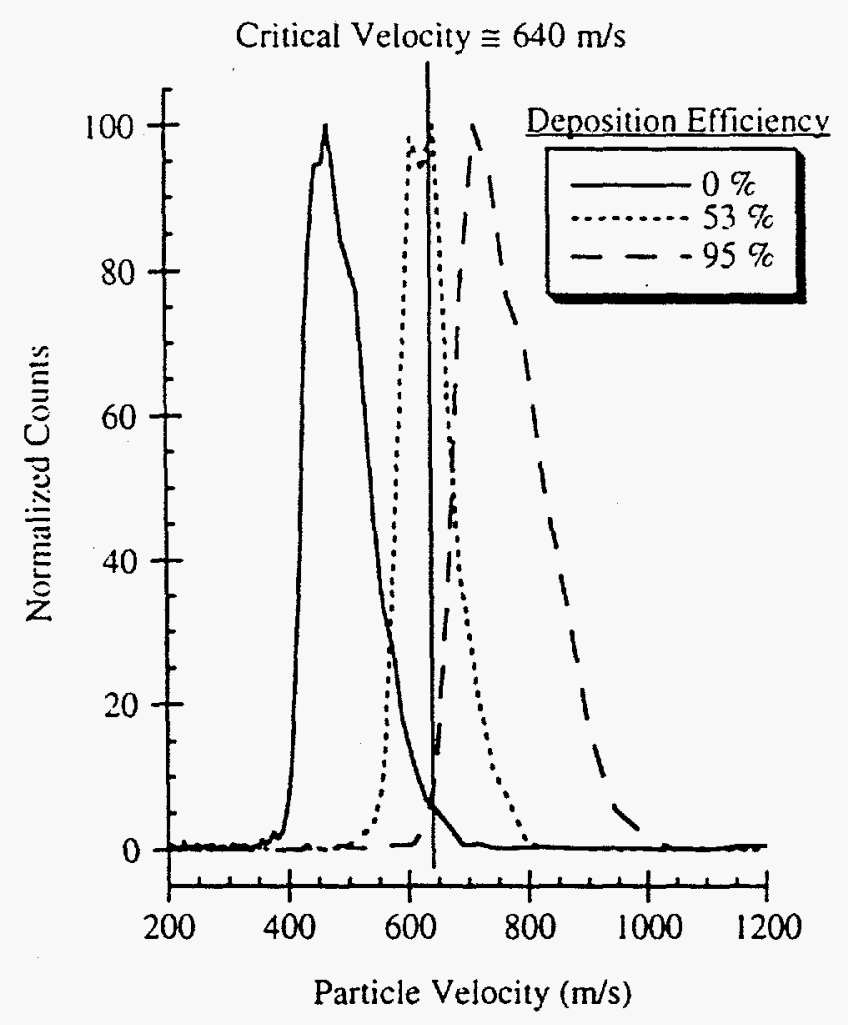


Figure $9 c$

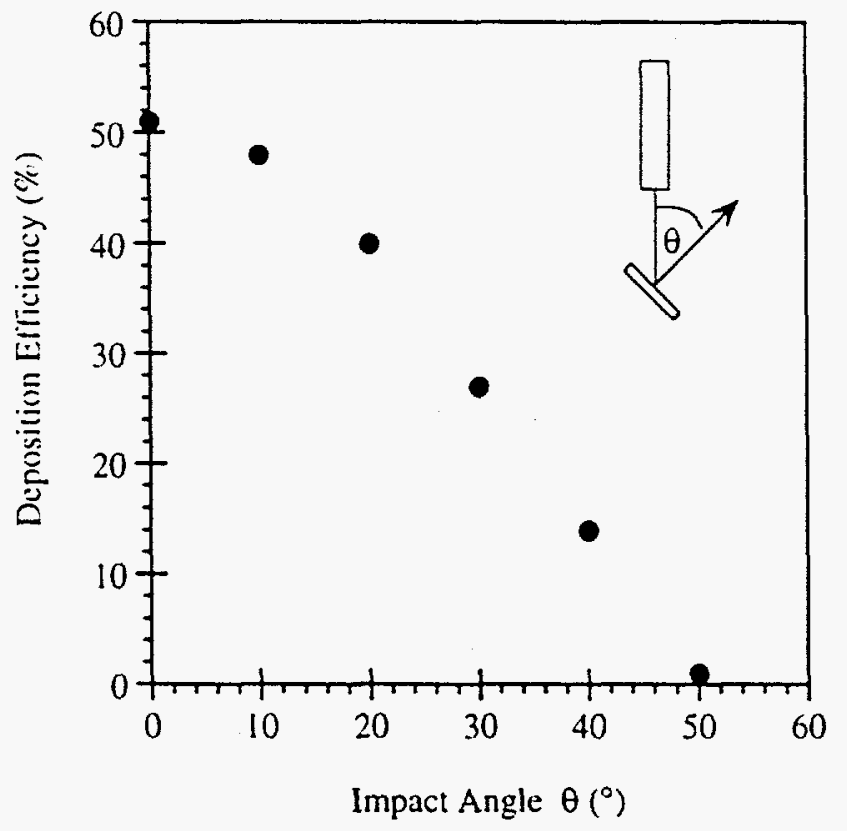


Figure 9d

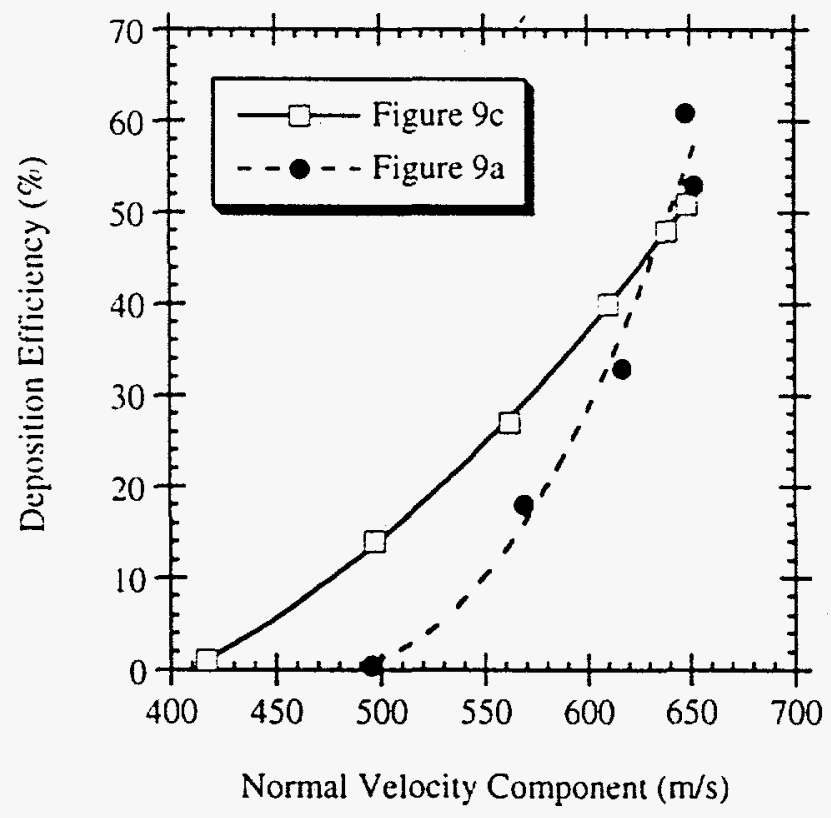

